The annual report is divided into three main sections, dealing with research and development, reactor design and construction, and administration, respectively. In general, the technical predictions on which the project was originally based continue to be confirmed by experience. No significant changes in the basic concept have been necessary, though an important change in the safety principles has been decided on. The inner containment, which consists of a steel shell containing the reactor core, is to be filled with air instead of nitrogen, but the design is such that a return to nitrogen filling, if required, can still be made. The reactor pressure vessel has been successfully pressure and leak tested and delivered to the site. Its erection within the reactor building is proceeding. Steady progress has been made in the design of the fission product and helium purification systems, and a contract for the purification plant is expected to be placed shortly. Construction of the reactor building has advanced rapidly and the control building has been completed.

Theoretical studies during the year have been concentrated on 'burn-up calculations' and power and tempera. ture distributions. The distribution of radioactivity in the Dragon system has been estimated. The experimental reactor physics investigations carried out in the Zenith reactor continued until July, when the exclusive use of the Zenith reactor for the Dragon programme came to an end. Several measurements have been made and evaluated. Heat-transfer channel experiments simulating Dragon reactor conditions have been carried out at Risø, Denmark. Carbon transfer experiments have emphasized the importance of extremely pure graphite in the core. Barium has been found to have a strong catalytic influence on graphite corrosion while silica acts as an inhibitor. The graphite for the main reactor components other than the fuel elements has been delivered and is in the process of being machined. No firm decision has yet been taken as to whether a fission product emitting fuel or a fission product retaining fuel will be used for the first charge in the Dragon reactor, but development work has proceeded on both types and plans for manufacturing either type are in hand.

The report contains many other details of the core and graphite assemblies and control mechanisms together with numerous dimensional diagrams and photographs of the various components. Annexed to the report are charts showing the composition of the staff of the Project; the members of the Board of Management and the General Purposes Committee - the two international committees responsible for the direction of the Project; and a list of all major contracts placed up to March 31, 1962.

\section{S. Weintroub}

\title{
RADIOACTIVITY IN HUMAN DIET
}

$\mathrm{ACH}$ year, as a reminder of the hazards of the atomic C age, reports are issued by the Agricultural Research Council Radiobiological Laboratory of levels of radioactivity in human diet. The annual report, 1961-62*, includes a review of research designed to give better understanding of factors which influence the passage of radioactive material from fall-out into plants and animals, both by direct contamination of foliage and via the soil, finally appearing in the mixed diet of the human population. The results of this work range from a demonstration that deposition of strontium-90 in soils may be reliably predicted from figures for annual rainfall, to a final indictment of the Brazil-nut as a concentrator of radium and thorium from the soil on which it is grown; about 1,000 times as much of these isotopes are found in Brazil-nuts as in other nuts and fruits.

The report gives the mean ratio of strontium-90 to calcium in the total mixed diet as 6.2 picocuries per gram of calcium during 1961 as compared with 6.4 in 1960 and 9.0 in 1959 , the corresponding values for milk being 5.9 , 6.4 and 9.7. It is stressed, however, that the figures obtained so far do not as yet reflect the full effects of the resumption of nuclear testing in 1961, and the most recent

* Agricuitural Research Council: Radiobiological Laboratory. Annual Report, 1961-62. Pp. Xv+96. (London: H.M. Stationery Office, 1962.) measurements support the forecast that the situation in 1962 will not differ greatly from that in 1959 after the tests in 1958.

Reference is made in the report to a 'working level', which is defined as 130 picocuries of strontium-90 per gramme of calcium. Indefinite exposure at this level would induce in bone amounts of strontium-90 of approximately half the maximum permissible specified by the Medical Research Council. In fact, the recommendation of the Medical Research Council's second report, The Hazards to Man of Nuclear and Allied Radiations (Cmnd. 1225, December 1960), was that "if the concentration of strontium-90 in bone calculated as an average for any age group, including the groups of infants and young children, was found to be rising continuously and to have reached the level of one-half that recommended as the maximum permissible level for the population as a whole, a reassessment of the situation would be required". The derivation of a 'working level' in the diet, from a maximum permissible level in bone, is not explained in the report from the Agricultural Research Council, and the size of the margin of safety adopted is not given.

In view of this the implications of the term "working level' are difficult to assess and at best this seems a most unfortunate choice of words.

\section{PETROLEUM MULCH}

$I^{N}$ $\mathrm{N}$ arboriculture the word 'mulch' is usually associated with the compost of wet leaves, straw, etc., laid as a protection to the roots of newly planted or young trees, especially on inherently dry soils. Petroleum mulch, however, is a relatively recent product of research in the industry and although in some respects its behaviour and purpose are similar to traditional soil-dressings, its potentialities are probably more far-reaching and durable. In the autumn number of the Esso Magazine (1962), an informative and well-illustrated account of a petroleum mulch evolved by Esso Research is given. The efficacy of this product is now being tested and proved on a large number of sites in many different countries. Already results are most encouraging and augur well for yet another application of petroleum to the well-being of mankind.

Briefly, this type of mulch is in fact an inexpensive emulsion of petroleum resins, used as an agricultural spray for improving the growth and yield of crops of all kinds. Its function is four-fold: to warm the soil, to reduce evaporation, to protect against soil-erosion, and to retard the dispersal by rain-wash and other agents of 